\title{
A review on chemistry and biological significance of benzimidaole nucleus
}

\author{
Nomi Srestha ${ }^{1}$, Janmajoy Banerjee ${ }^{1}$,Sujiti Srivastava ${ }^{1 .}$ \\ ${ }^{I}$ Department of pharmacy, Sunsari Technical College,Daran ,NEPAL
}

\begin{abstract}
Benzimidazole is a heterocyclic aromatic organic compound. It is an important pharmacophore and privileged structure in medicinal chemistry. It plays a very important role with plenty of useful therapeutic activities such as: antiulcers, antihypertensives, analgesic, anti-inflammatory, anti-virals, antifungals, anticancers, and antihistaminics. The review of the literature shows that the benzimidazole derivatives are outstandingly effective compound and number of reviews available for biochemical and pharmacological studies conformed that their molecules are useful against a wide variety of micro-organisms. Because of their importance, the methods for their synthesis have become a focus of Synthetic Organic Chemists. Therefore in the present review we tried to compile the chemistry of different derivative of substituted benzimidazole as well as various pharmacological activities and some of the important methodologies used for the synthesis.
\end{abstract}

KEYWORDS- pharmacophore,Benzimidazole, anti-hypertensive, anti-histaminic,

\section{INTRODUCTION:}

Benzimidazole is a heterocyclic aromatic organic compound. It is important pharmacophore and a privileged structure in medicinal chemistry. This compound is bicyclic in nature which consists of the fusion of benzene and imidazole. Now adays is a moiety of choice which possesses many pharmacological properties ${ }^{[I]}$. The most prominent benzimidazole compound in nature is N-ribosyl-dimethylbenzimidazole, which serve as an axial ligand for cobalt in vitamin ${ }^{[1,2,3]}$.<smiles>c1ccc2[nH]cnc2c1</smiles>

Fig: 1H-Benzimidazole

This important group of substances has found practical applications in a number of fields: analgesic ${ }^{[4,5,6]}$, anti inflammatory ${ }^{[5,6,7,8]}$, antibacterial ${ }^{[9]}$, antifungal ${ }^{[10]}$, antiviral ${ }^{[11,12]}$, anti-helmenthic ${ }^{[13],}$ anticonvulsant ${ }^{[14,15]}$, anticancer $^{[16,17]}$, antiulcer ${ }^{[18]}$ antihypertensive ${ }^{[19]}$. . Historically, the first benzimidazole was prepared in 1872 by Hoebrecker, who obtained 2,5(or 2,6)-dimethylbenzimidazole(fig below) by the reduction of 2-nitro-4methylacetanilide ${ }^{[20,21]}$.<smiles>CNc1ccc(C)cc1N</smiles>

Fig: Synthesis of 2,5 (or 2,6)-dimethylbenzimidazole 


\section{Spectral properties of benzimidazoles}

1) Infra red (IR) spectroscopy: The absorption spectra of benzimidazole near the $2850 \AA$ indicates the presence of the aryl ring , absorption near the $3107 \AA$ indicates the presence of $\mathrm{N}-\mathrm{H}$ stretch and $1690 \AA$ indicates the presence of $\mathrm{C}-\mathrm{N}$ stretch.

2) Mass spectroscopy: The fragmentation pathways of simple benzimidazoles are similar to those of imidazoles. The spectrum of benzimidazole indicates a sequential loss of two molecules of hydrogen cyanide from the molecular ion, the first of which is nonspecific as evidenced by deuterium labeling procedures. A characteristic feature in the fragmentation of 2-n-propylbenzimidazole is the elimination of ethylene from the molecular ion, 2-acylthiophenes, 2-acyl and 2- benzoylbenzimidazoles are characterized by loss of carbon monoxide from the molecular ion.

3) Nuclear magnetic resonance (NMR) spectroscopy: An important feature of this work is that the protonation parameters derived from simple five and six membered heterocycles can be used to predict chemical shift changes resulting from nitrogen protonation and deprotonation in more complex molecules. $87-9$ values shows multiplet indicates the presence of benzimidazole aryl ring.

4) 13Carbon NMR: The spectra shows different carbon peaks at range of $\delta 0-200$ compared to TMS. For benzimidazoles the range starts from $\delta 115-144$.Overlapping is easily confirmed by triplet, doublet peaks obtained. Low intensity peaks show the presence of proton less carbons. So carbonyl group at which position is recognized $^{[21]}$.

Physical properties of benzimidazoles: The melting point of number of the benzimidazoles indicated that the introduction of a substituent into 1-position in general lowers the melting point. Benzimidazoles with the imide nitrogen are usually soluble in polar solvents and less soluble in organic solvents. With introduction of other non-polar substituents in various positions of the benzimidazole ring, the solubility in nonpolar solvents is increased. Conversely, the introduction of polar groupings into the molecule increases solubility in polar solvents. Benzimidazole distills unchanged above $300^{\circ} \mathrm{C}$. Benzimidazoles are weakly basic, being somewhat less basic than the imidazoles and are in general soluble in dilute acids. Benzimidazoles are also sufficiently acidic to be generally soluble in aqueous alkali and form $\mathrm{N}$-metallic compounds. The acidic properties of the benzimidazoles, like those of the imidazoles, seem to be due to stabilization of ion by resonance. The more acidic benzimidazoles may be soluble in less basic solution, such as potassium carbonate solution ${ }^{[20-21]}$.

\section{Chemical properties of benzimidazoles ${ }^{[2 l]}$}

Reactions of the benzimidazole ring: The benzimidazole ring possesses a high degree of stability. Benzimidazole is not affected by concentrated sulfuric acid, hot hydrochloric acid as well as alkalis. Oxidation cleaves the benzene ring of benzimidazole only under vigorous conditions. The benzimidazole ring is also quite resistant to reduction except under certain considerations.

Reactions involving 1 and 3-positions: Benzimidazoles form salts e.g. with acids readily forms monohydrochloride, mononitrate, monopicrate, monoacetate.

Alkylations: Benzimidazoles, undergoes alkylation with alkyl halides, yielding 1-alkylbenzimidazoles and under more vigorous conditions, 1,3-dialkylbenzimidazolium halides.

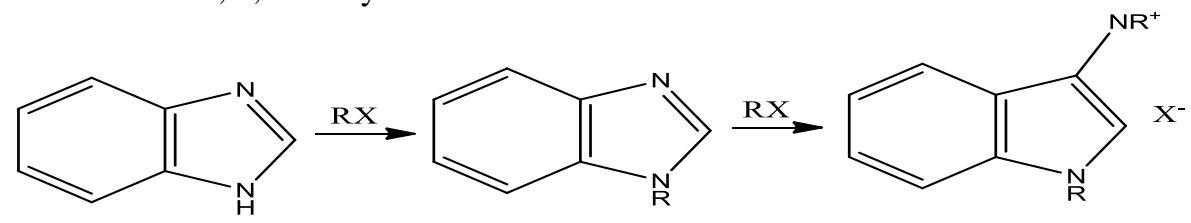

Fig: Alkylation of benzimidazole

Benzimidazoles also react with acylating, Grignard reagents and metal. The benzimidazole also forms mannich bases by reacting formaldehyde and piperidne.

Hydrogenation and dehydrogenation reactions: Until very recently it was thought that benzimidazole ring was stable to reduction. Catalytic reduction of benzimidazole even under high pressure with nickel as the catalyst is reported to give negative results. 2-Phenylbenzimidazole gives only 2-cyclohexylbenzimidazole. Hydrogenation of 2-( $p$-dimethylaminostyryl) benzimidazole with nickel at atmospheric pressure saturates only the olefinic linkage in the 2-positions. 


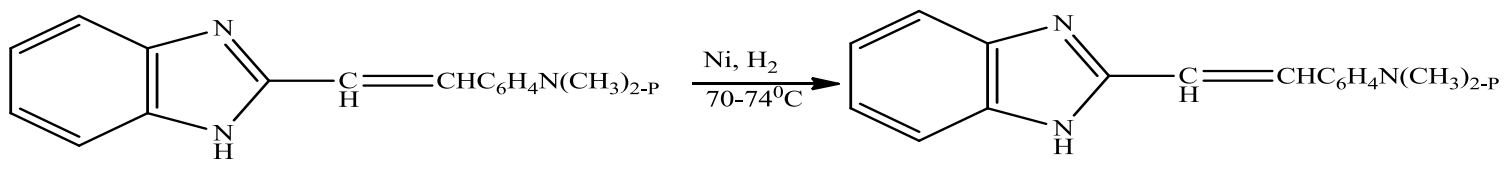

Fig: Hydrogenation of benzimidazole

A number of hydrogenated benzimidazoles have been prepared also by chemical methods. Hexahydro- $2(3 H)$ benzimidazolone may be obtained by the reaction between hexahydro-o-phenylenediamine and phosgene in sodium hydroxide solution. Attempted dehydrogenation of tetrahydrobenzimidazoles with palladium sponge does not give the corresponding benzimidazole but instead a compound of high molecular weight.

Cleavage of the imidazole ring: The imidazole ring of benzimidazoles may be cleaved by reacting with pseudobases, acid anhydrides and halide.

Halogenation: When 2,5(or 2,6)-dimethylbenzimidazole is an aqueous acid solution on treatment with saturated solution of bleaching powder at $0-5^{\circ} \mathrm{C}$. 1-chloro-2,5(or 2,6)-dimethylbenzimidazole is obtained.<smiles>Cc1ccc2[nH]c(CC(=O)OCc3ccccc3)nc2c1</smiles>

Fig: Halogination of benzimidazole

Reactions involving the 2-methyl or methylene group: The methyl group of 2-methylbenzimidazoles is comparable in its activity to the methyl group of $\alpha$-picoline, quinaldine, or methyl ketones and shows most of the same reactions of these compounds. The benzimidazoles ring, like the pyridine and quinoline ring, because of its electron attracting nature imparts a positive character to the carbon atom of the 2-methyl group.

Nitration: In most cases nitration appears to take place preferentially at the 5 or 6 positions. However, the nitro group may also enter the 4 or 7 position, especially if the 5 or 6 position is blocked.

Reactions involving substituent groups: The various useful transformations can be successfully carried out various substituents in benzimidazoles. Some of the conversions are discussed below:<smiles>Cc1ccc2[nH]c(CC(C)C)nc2c1</smiles>

Fig: Reaction involving the 2-methyl or methylene group

(1) Reactions of 2-benzimidazolecaboxylic acids: Benzimidazoles containing a carboxyl group in the 2positions readily undergo decarboxylation on heating. 2-benzimidazolecarboxylic acid on heating above its melting point, for example, yields benzimidazoles.

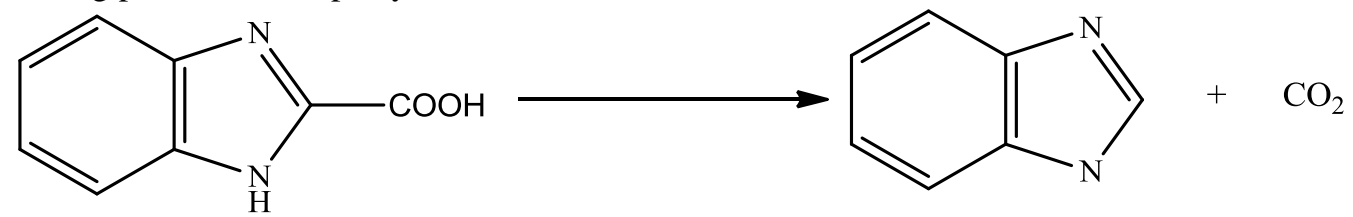

Fig: Reaction of 2-benzimidazole carboxlic acids 
(2) Reactions of 2-( $\alpha$-haloalkyl)benzimidazoles: 2-( $\alpha$-Chloroisopropyl) benzimidazole when refluxed in dry alcoholic solution in the presence of pyridine gives a good yield of 2 -( $\alpha$-ethoxyisopropyl)benzimidazoles and hence reacts in a manner analogous to tritylchloride (triphenylmethyl chloride).

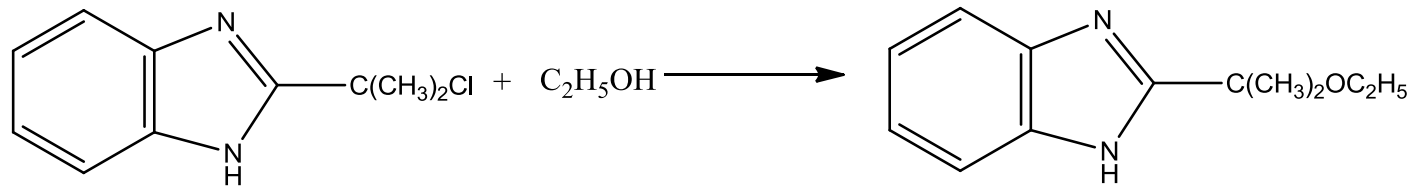

Fig: Reaction of 2-(a-haloalkyl) benzimidazoles

(3)

Reactions of 2-(3H)-Benzimidazolones: 2(3H)-

Benzimidazolones (or 2-hydroxybenzimidazoles) are extremely stable treatment of substances.2 (3H)benzimidazolone is not split by treatment with benzoyl chloride in alkaline solution. $2(3 H)$ benzimidazolones show many of the reactions of 2-hydroxypyridines and 2-hydroxyquinolines; for example, 2(3H)-benzimidazolone with phosphorous oxychloride or phosphorous pentachloride yields the 2-chloro derivative.<smiles></smiles><smiles>C=CCc1ccc2[nH]c(Cl)nc2c1</smiles>

Fig: Reaction of 2-(3H)-benzimidazoles

(4) 2(3H)-Benzimidazolethiones: 2(3H)-Benzimidazolethiones or 2- mercaptobenzimidazoles) are generally stable substances and are soluble in dilute alkali. Alkylation occurs readily with replacement of the mercapto hydrogen to yield S-alkylated derivatives, and a number of these derivatives have been prepared.<smiles></smiles>

Fig: Reaction of 2(3H)-benzimidazilethione

(5) 2-Aminobenzimidazoles: 2-Aminobenzimidazole with acetic anhydride gives 2-acetyl aminobenzimidazole.<smiles>Nc1nc2ccccc2[nH]1</smiles><smiles>CC(=O)Nc1nc2ccc(C=COC(C)=O)cc2[nH]1</smiles>

Fig: Reaction of 2-Aminobenzimidazoles

(5) Oxidation: Benzimidazoles are stable to oxidation. By vigorous conditions of oxidation (potassium permanganate in hot alkaline solution) it is partially possible to oxidize benzimidazoles to obtain a small amount of imidazoledicarboxylic acid.

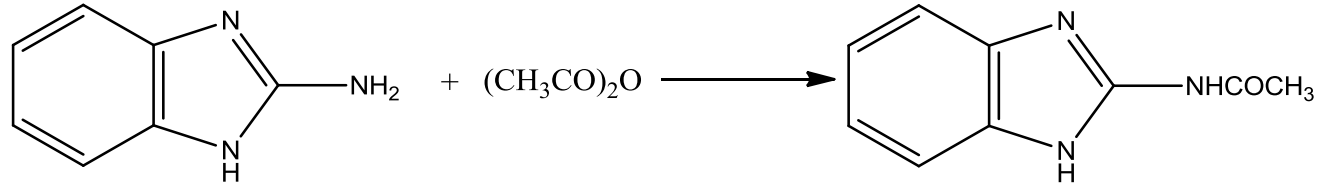

Fig: Reaction of Oxidation of benzimidazole 
Because of the stability of the benzimidazoles ring to oxidation it is possible to oxidize substituent group without affecting the ring. By the oxidation of the substituent groups a variety of benzimidazolecarboxylic acids have been prepare ${ }^{[20,21]}$.

\section{Methods for synthesis of benzimidazole derivatives}

* Komal P et al ${ }^{[22]}$,. have reported the synthesis of 2-chloromethyl-1H-benzimidazole by condensing 2chloromethyl-1H-benzimidazole with different aromatic amines and heterocycle.

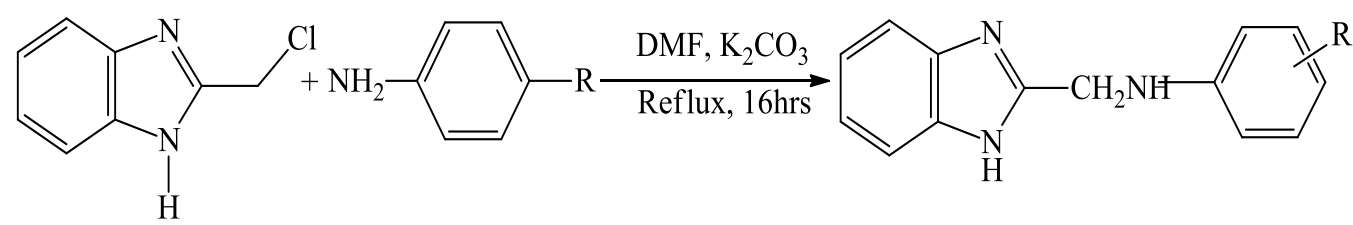

* Soni B et $a l^{[23]}$., reported synthesis of a novel series of N'-(substituted benzylidene)-2-[2-(substituted phenyl)-1H-benzimidazol-1-yl] acetohydrazide.

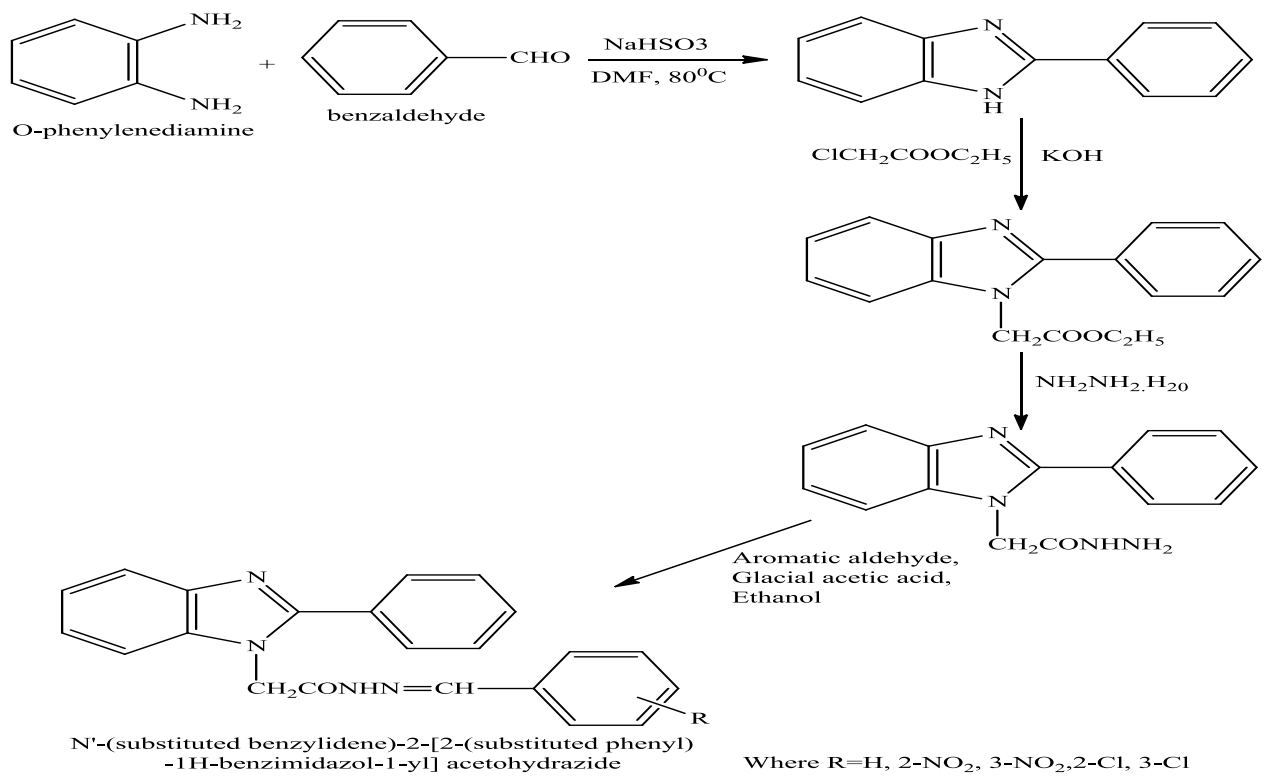

* Synthesis of benzimidazole as 2-substituted benzimidazole derivatives was reported by Panneer Selvam et al ${ }^{[24]}$.<smiles>Nc1ccccc1N</smiles>

o-phenylene diamine

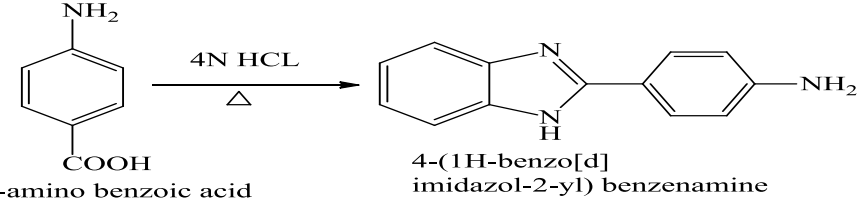

Ar-CHO

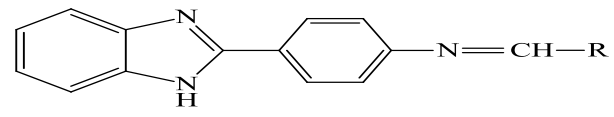

N-(4-substituted benzylidine)-4-

(1H-benzo[d]imidazol-2-yl) benzenamine

$\mathrm{ClCH}_{2} \mathrm{COCl}$

$\left(\mathrm{C}_{2} \mathrm{H}_{5}\right)_{3} \mathrm{~N}$

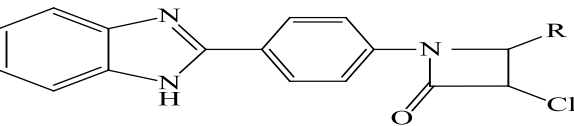

-(4-(1 Hbenzo[d] imidazol-2-yl) phenyl)-3-chloro-4-(4substituted phenyl) azetidin-2-one 
* Marriappan $G$ et al ${ }^{[7]} .(2011)$, have reported the synthesis of [1-(N-subistituted amino)methyl]-2-ethyl benzimidazole derivative(1-10) by the condensation of 2-ethyl benzimidazole with primary/secondary amines.
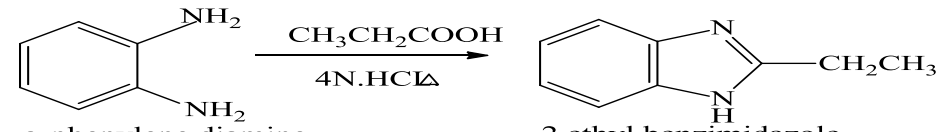

o-phenylene diamine

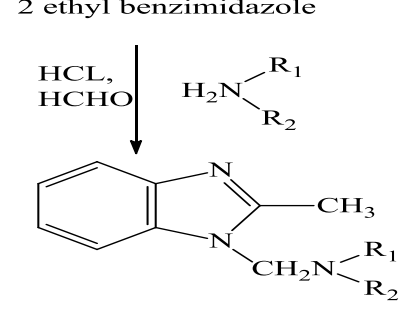

[1-(N-substituted amino)-methyl]-

2-ethyl benzimidazole

A new series of 2, 5 di-substituted benzimidazole derivatives have been reported by Sugumaran M et al ${ }^{[25]}$.

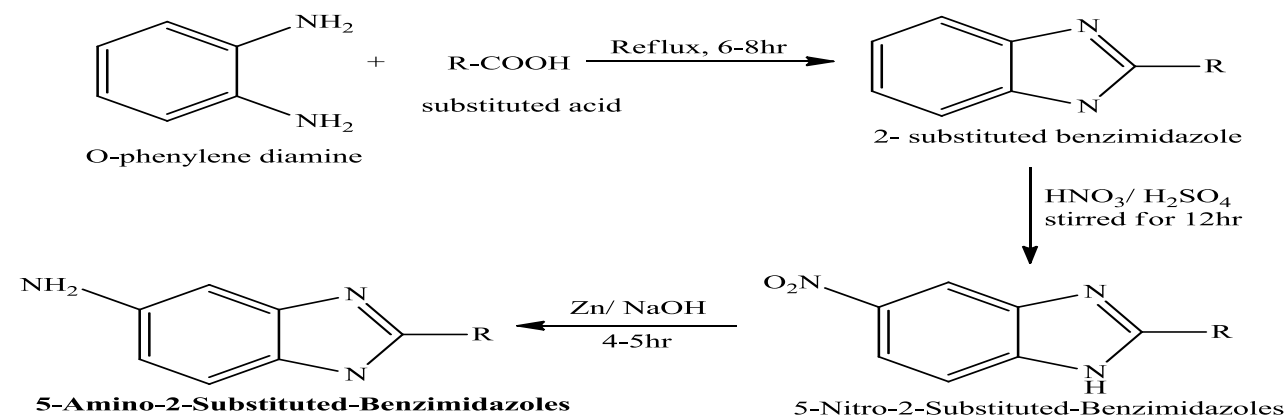

Sudheer Babu I et al ${ }^{[26]}$, reported synthesis of 1-substituted benzimidazoles derivatives in the yield ranged from $52-76 \%$ which were prepared by mannich reaction with benzimidazole derivatives, formaldehyde and different aromatic amines .

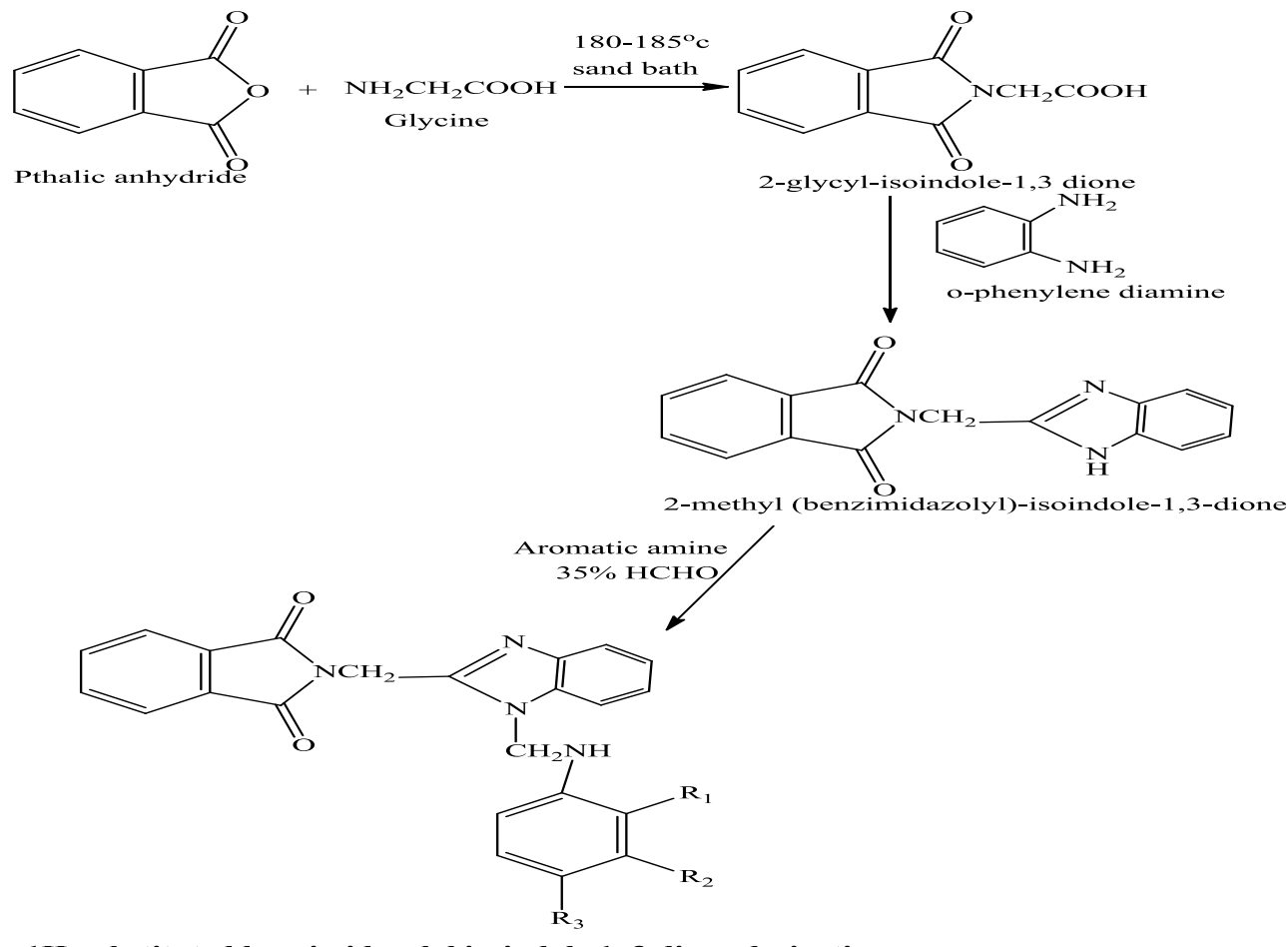


* Chimirri A et $a l^{[11]}$., have reported the synthesis of novel $1 H, 3 H$-thiazolo[3,4-a]benzimidazole derivatives substituted on the benzene-fused ring.

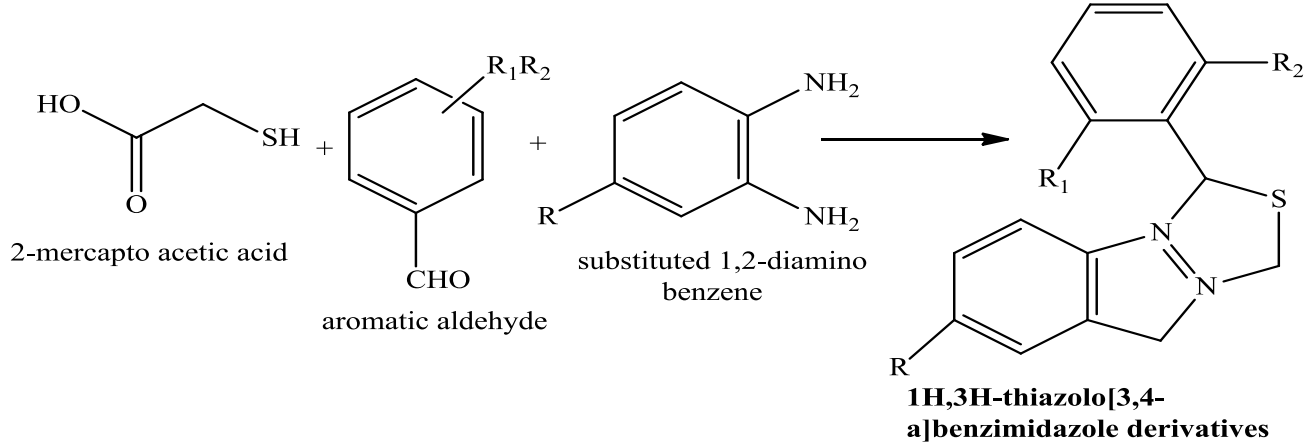

* Sanahanbi N et $a l^{[6]}$., have reported the synthesis of some Schiff's Bases of 2-methyl benzimidazole derivatives.
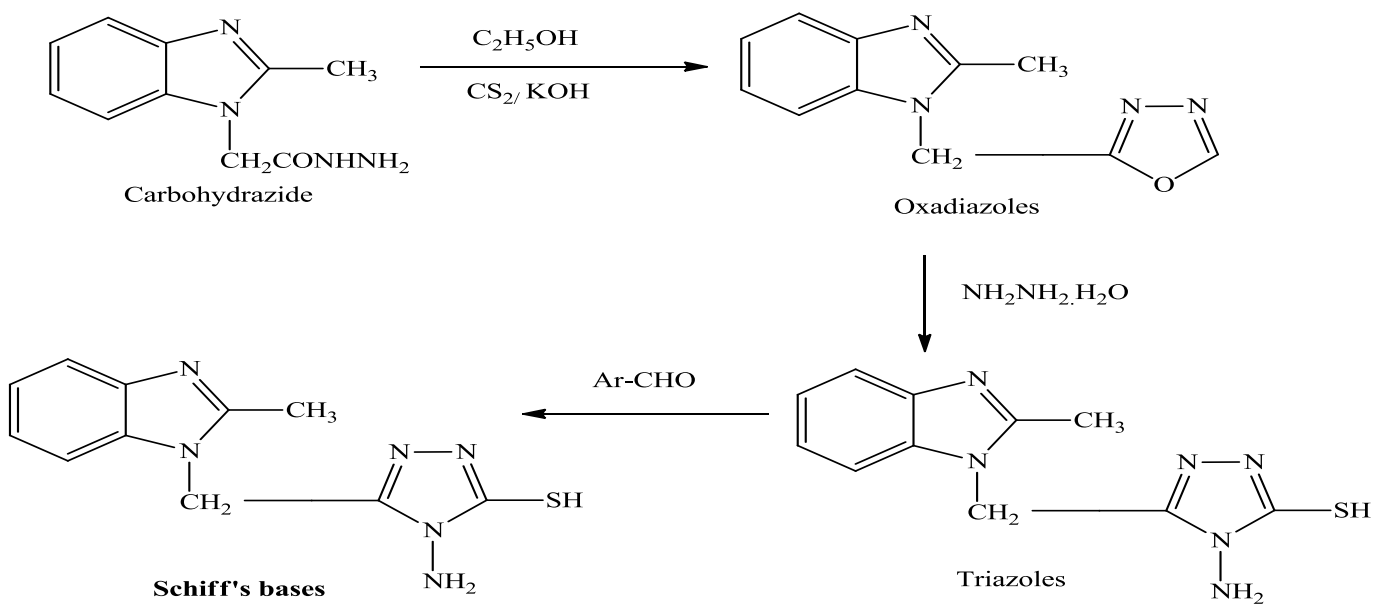

- Kuldeep Kumar* and Prof.(Dr). D. P. Pathak ${ }^{[27]}$., have reported the synthesis of some new 2substituted benzimidazole derivatives from microwave irradiation method by condensation of 2 nitroaniline with different carboxylic acids (aliphatic,aromatic and hetrocyclic).<smiles>Nc1ccccc1[N+](=O)[O-]</smiles>

2-nitro aniline

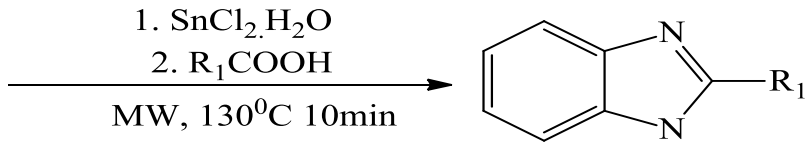

2- substituted benzimidazole

- Davood Azarifar et al ${ }^{[28]}$., have reported for the green synthesis of various 2-aryl-1-(arylmethyl)-1Hbenzimidazoles in high yields by acetic acid-promoted condensation of $o$-phenylenediamine with aldehydes in air under microwave irradiation.

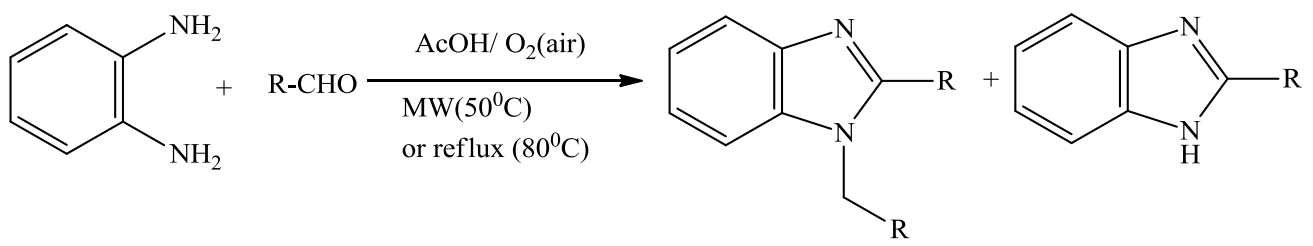


* K.C.S. Achar et al ${ }^{[29]}$., have reported the synthesis of series of 2-methylaminobenzimidazole derivatives (1-11) by the reaction of 2-(chloromethyl)-1H-benzimidazole derivatives with primary aromatic amines.

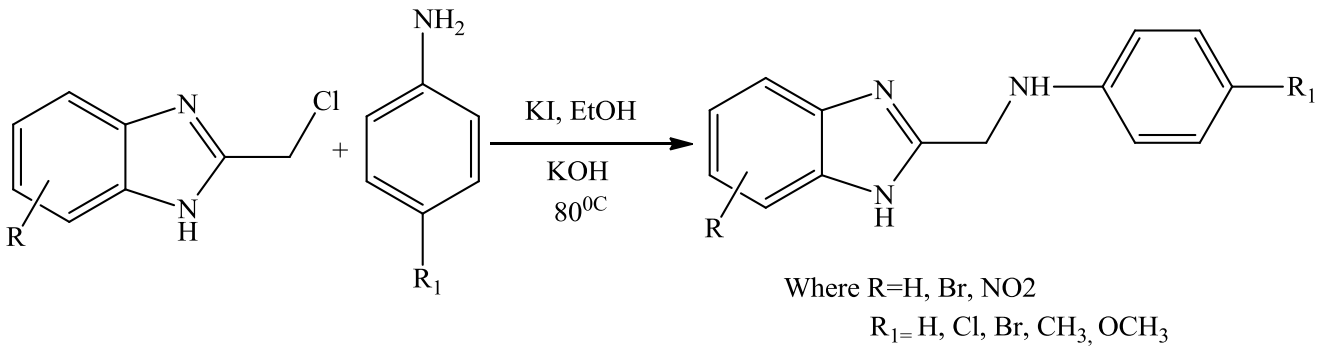

\section{Pharmacological activity of benzimidazole derivatives:}

\section{Analgesic and anti inflammatory}

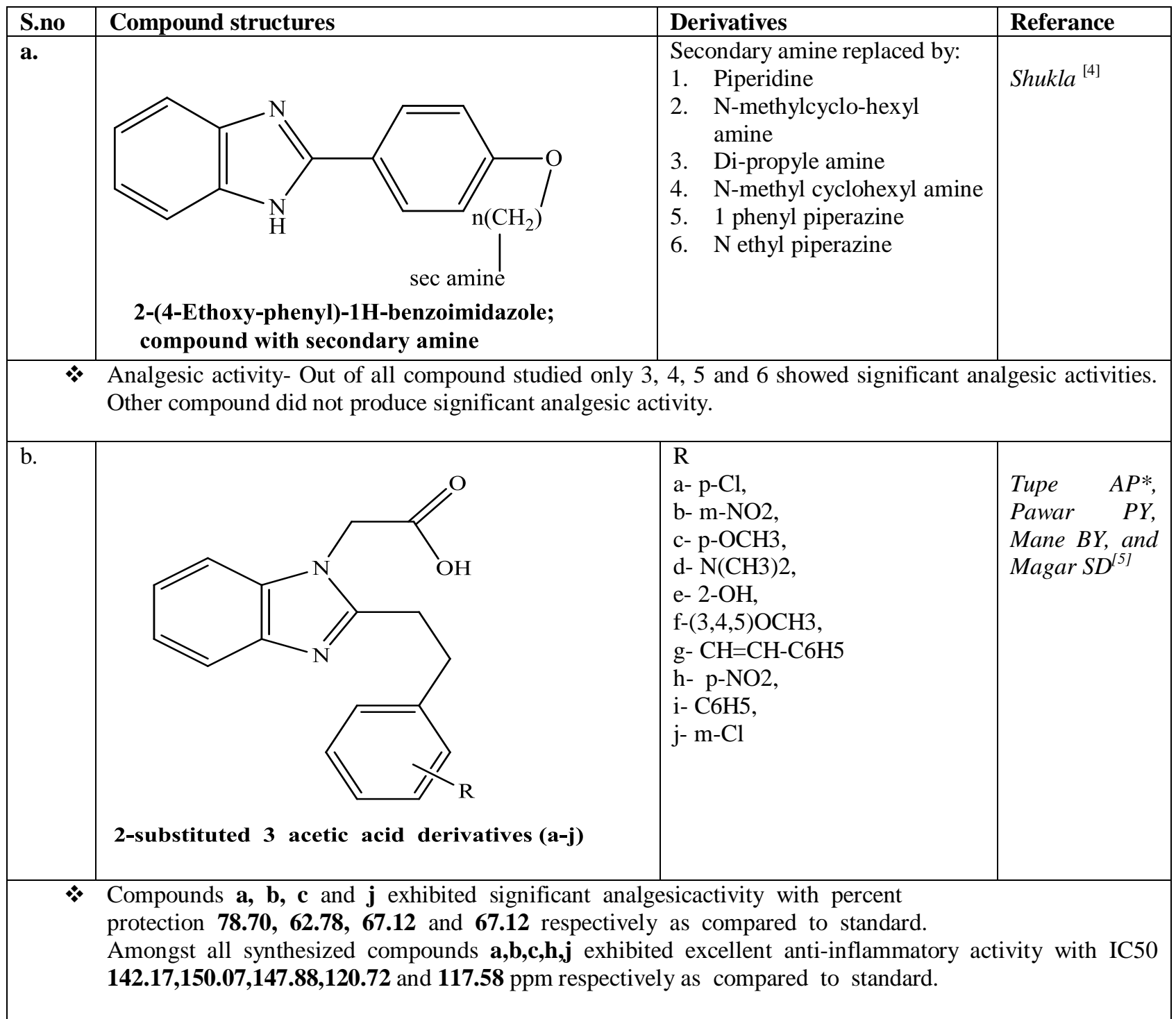




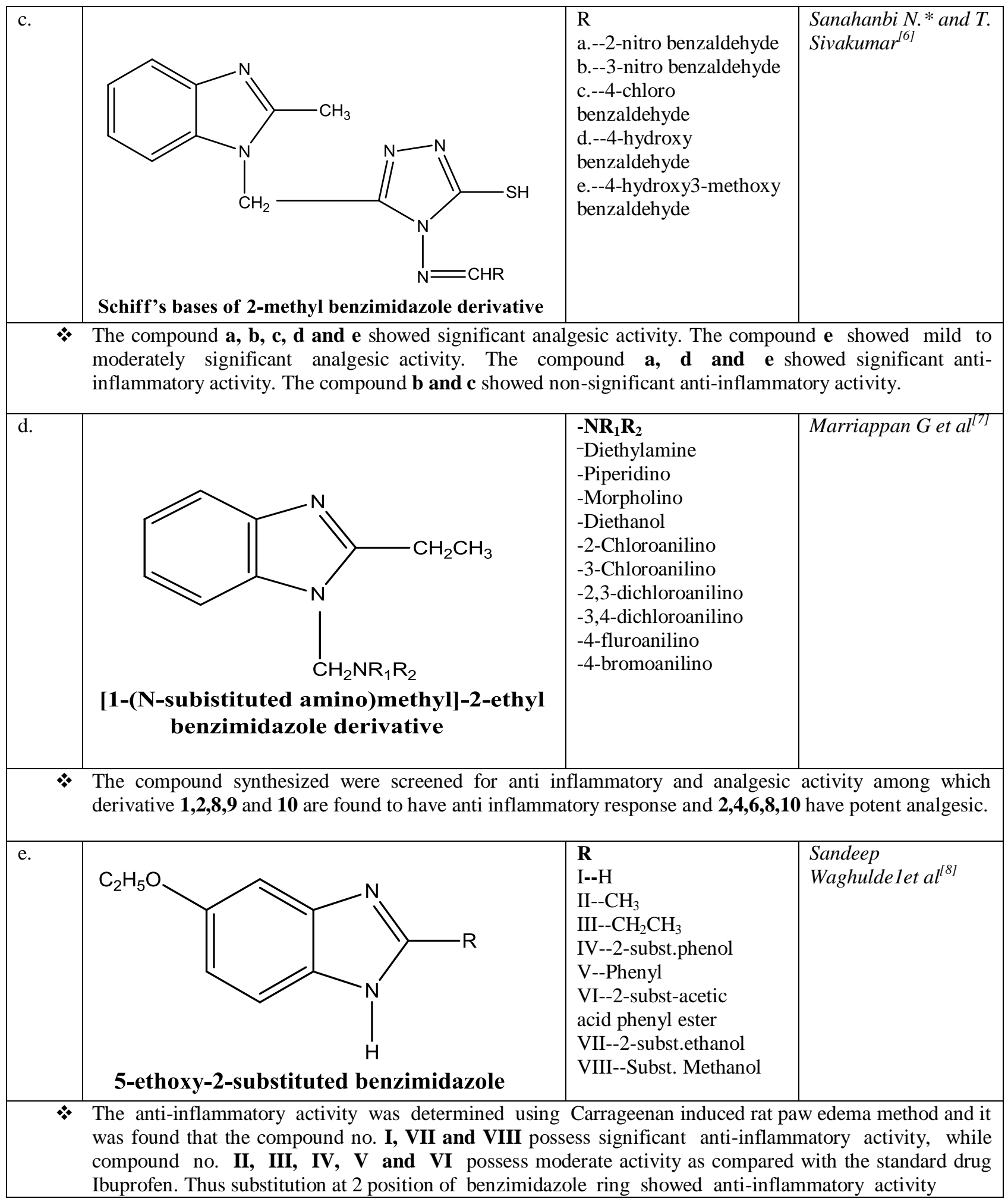




\section{Anti bacterial and anti fungal activity}

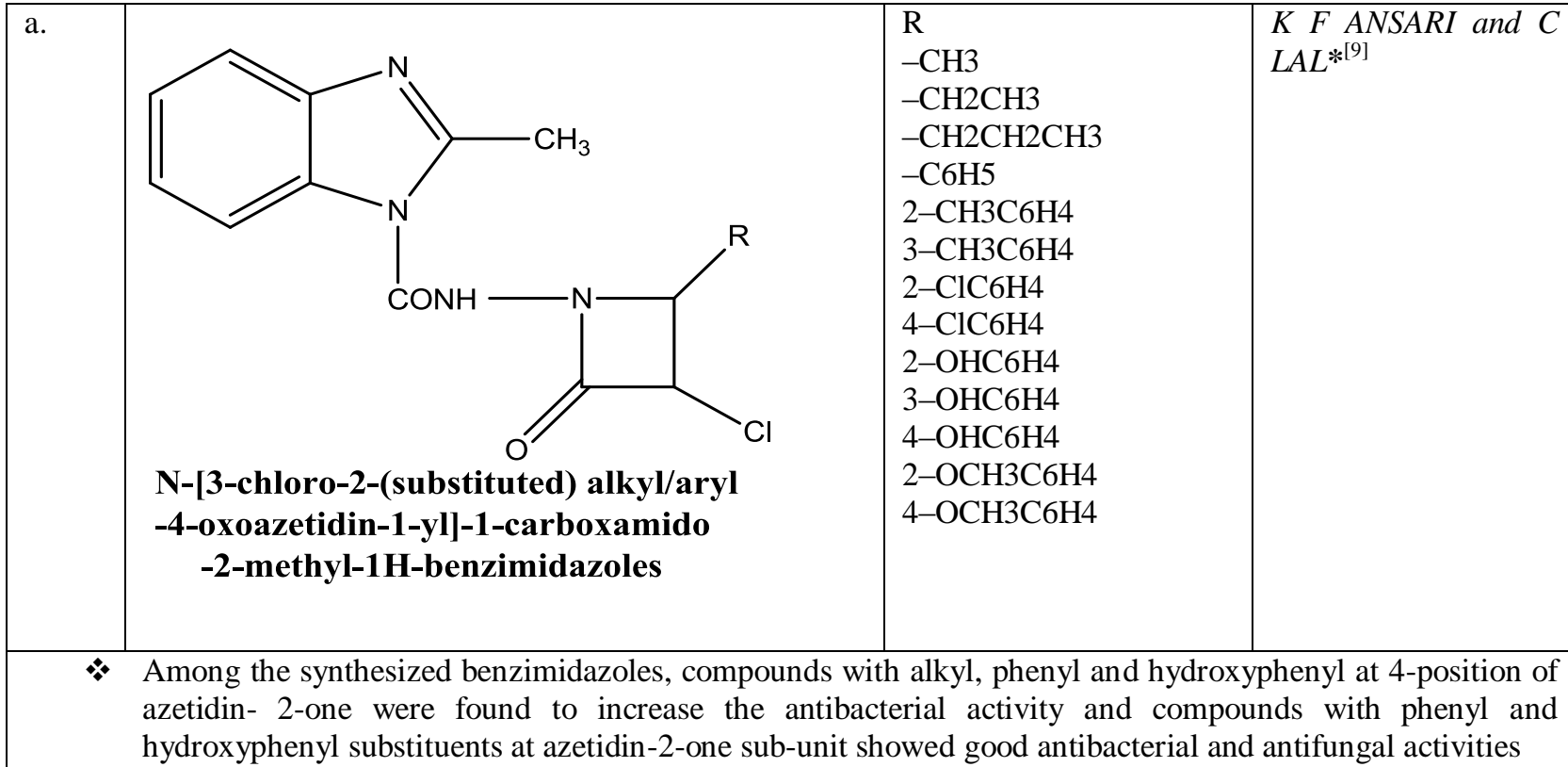

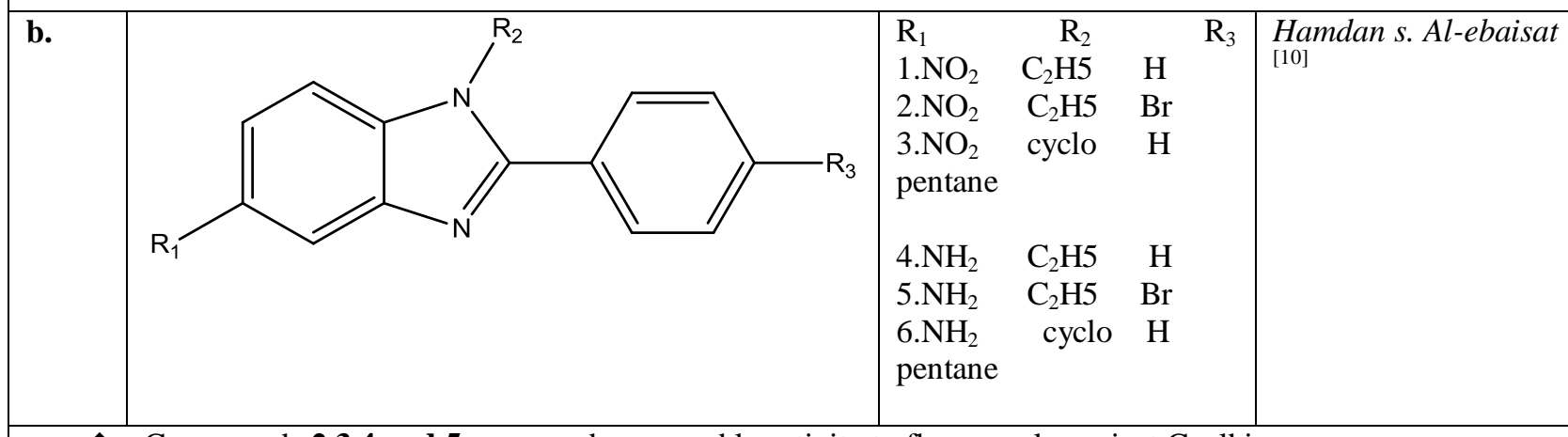

* Compounds $\mathbf{2 , 3 , 4}$ and 5 possessed comparable activity to fluconazole against $C$. albicans.

c.<smiles>[R]CCn1c(-c2ccccc2)nc2ccccc21</smiles>

$\mathrm{N}^{\prime}$-(substituted benzylidene)-2-[2-(substituted phenyl) -1H-benzimidazol-1-yl] acetohydrazide

From the antibacterial activity study, it was observed that compound c showed minimum activity and compounds $\mathbf{b}$ and $\mathbf{e}$ showed better activity thus concluding that the compound having p-chloro substituent is the most potent followed by o-chloro, unsubstituted, 3-nitro and 2- nitro group. 
A review on chemistry and biological...

\begin{tabular}{|l}
\hline All synthesized compounds were screened for antibacterial and antifungal activity. Some of the tested \\
compounds exhibited potent to moderate antibacterial activity against both (Gm+ve) S.aureus, S.pyogenus \\
and (Gm-ve) E.coli, p.auregensa when compared to standard Ampicilline. Few of the tested compounds \\
exhibited significant and potent antifungal against C. albicans but none of synthesized compounds shown \\
significant antifungal activity against A. Niger and A.clavatus when compared to standard griseofulvin.
\end{tabular}

\section{Anti viral activity}

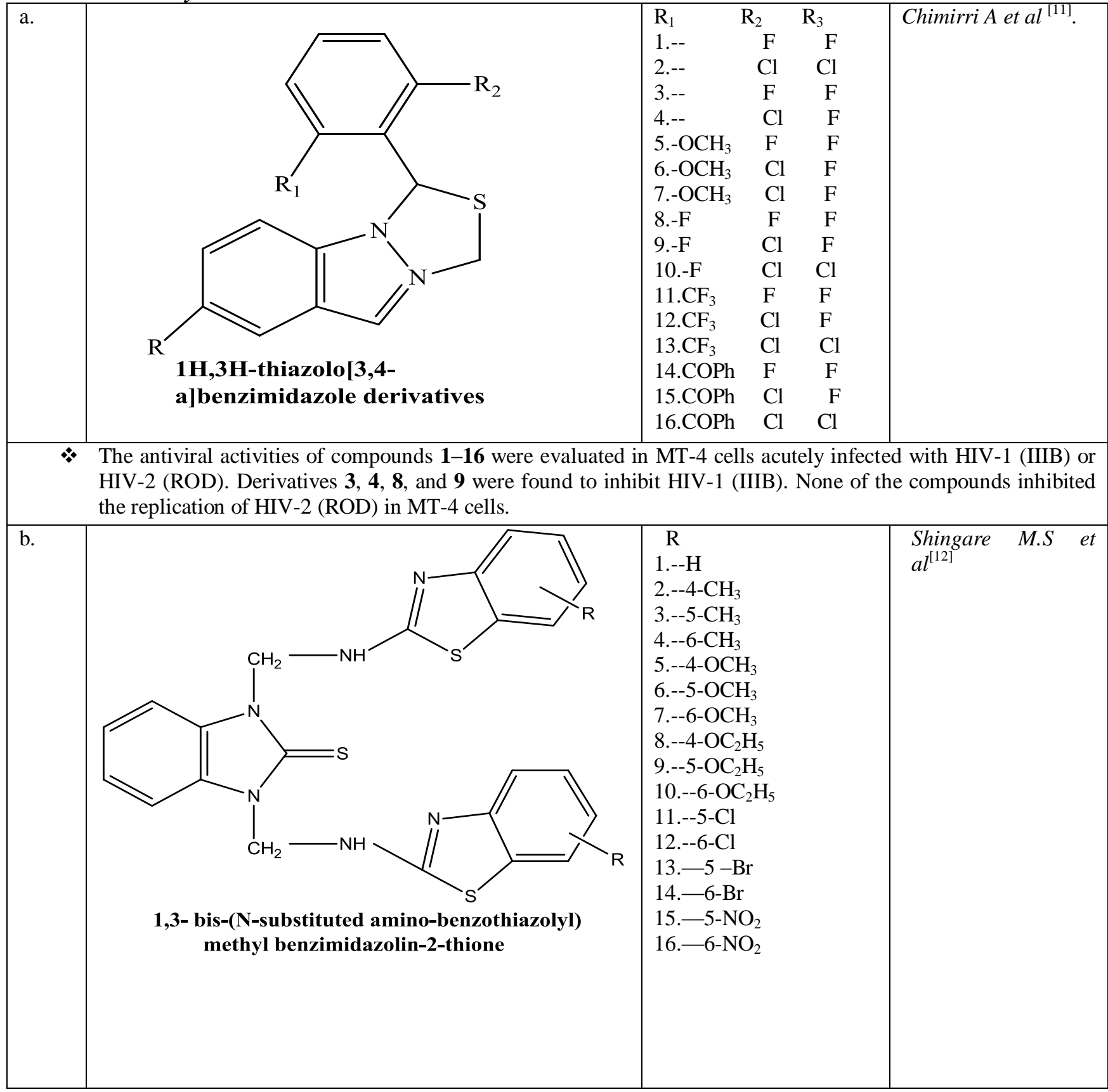


* It was established that the benzothiazole moiety having $-\mathrm{OCH}_{3},-\mathrm{OC}_{2} \mathrm{H}_{5},-\mathrm{NO}_{2}$ groups shows good activity against TMV and CGMMV invitro and invivo. The benzothiazole moiety having groups such as $\mathrm{H},-\mathrm{CH}_{3},-\mathrm{Cl},-$ Br shows moderate activity.

4.Antihelmenthic activity

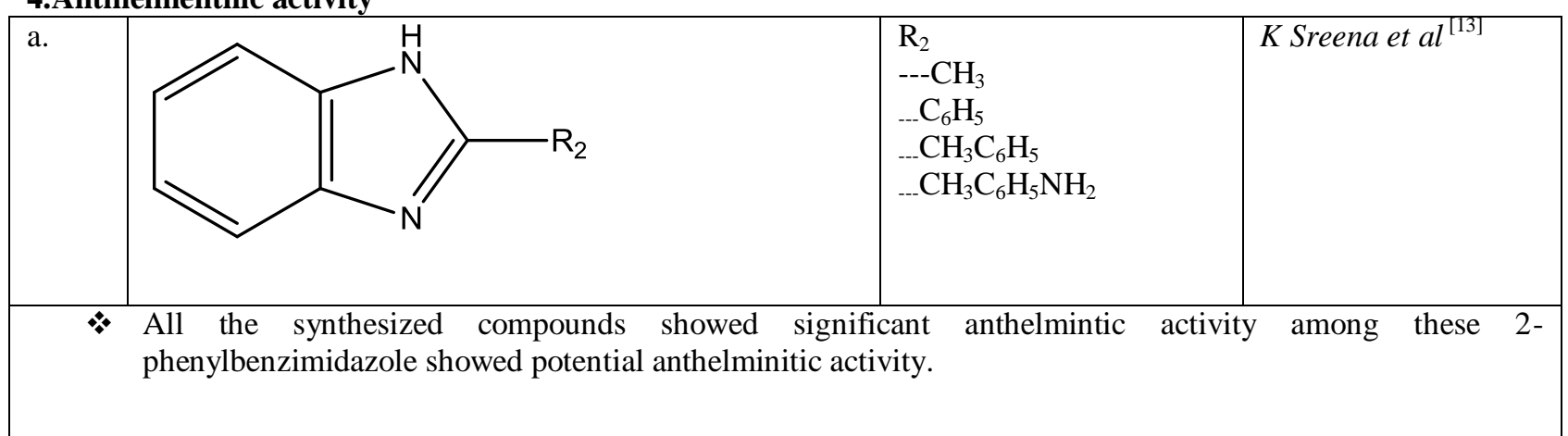

\section{Anti convulsant activity}

*.
The study of various physicochemical properties indicates that the change in linker at position one (R1) does
not change the activity of the synthesized compounds and optimum chain length at position two (R2) is
responsible for the anticonvulsant activity. The results also showed that the synthesized compounds with
electron withdrawing group such as nitro at position five (R3) have been reported to possess better anti-
convulsant activity as predicted by QSAR studies.

6. Antihypertensive activity

Fom
From the study it was found that compounds that contain ethyl at position -2 gave better result than 2-
phenyl. In the biphenyl ring carboxylic group at ortho position is necessary for pharmacological activity. At
2' position tetrazolyl moiety had the best pharmacological activity was found in the literature. At position 5
of benzimidazole NH2 group gives good activity.




\section{Antiulcer activity}

\begin{tabular}{|c|c|c|c|}
\hline a. & $\begin{array}{l}\text { 2-[5-substituted-1-H-benzo(d)imidazol-2-yl } \\
\text { sulfinyl]methyl-3-substituted quinazoline-4- } \\
\text { (3H)-one derivatives }\end{array}$ & 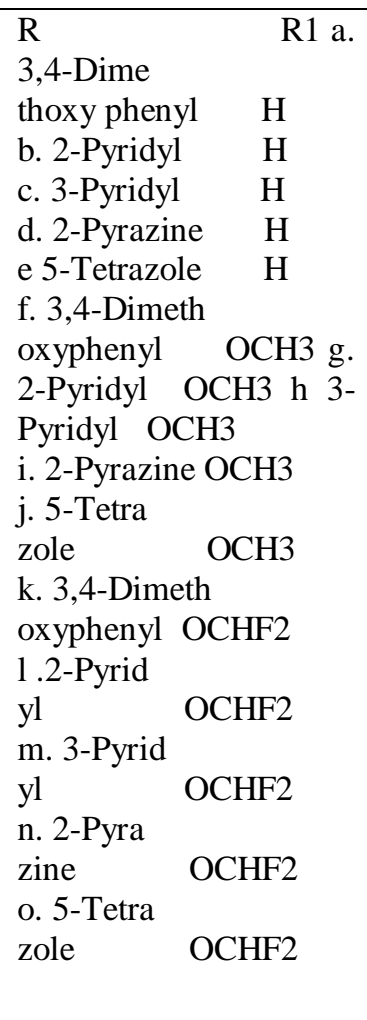 & $\begin{array}{lr}\text { Avinash } & \text { Patil, } \\
\text { Swastika } & \text { Ganguly } \\
\text { and } & \text { Sanjay } \\
\text { Surana }^{[32]} & \end{array}$ \\
\hline & $\begin{array}{l}\text { Compounds } \mathbf{k} \text { and } \mathbf{n} \text { showed most potent activity a } \\
\mathrm{ng} / \mathrm{kg} \text {. Compounds a, } \mathbf{d}, \mathbf{i}, \mathbf{l} \text { and } \mathbf{o} \text { showed moder } \\
\mathrm{ng} / \mathrm{kg} \text { dose showed less ulcer index. Mostly compc } \\
\text { and } \mathrm{l} \text { at } 20 \mathrm{mg} / \mathrm{kg} \text { doses inhibited acid secretion }\end{array}$ & $\begin{array}{l}\mathrm{d} \text { to Omeprazole at th } \\
\mathrm{y} \text { at the same doses. } \\
\mathbf{l}, \mathbf{n} \text { and } \mathbf{o} \text { at } 10 \mathrm{mg} / \mathrm{k}\end{array}$ & $\begin{array}{l}\text { e level of } 10 \text { and } 20 \\
\text { bounds } \mathbf{i}, \mathbf{k}, \mathbf{n} \text { at } 20 \\
\text { compounds } \mathbf{i}, \mathbf{k}, \mathbf{n},\end{array}$ \\
\hline
\end{tabular}

\section{Referance:}

[1]. Babita Goswami et al., Pharmacological activities of benzimidazole derivatives- Overview, IJSID, 2012, 2 (1), $121-136$

[2]. Manna K, Aggarwal Y. Microwave assisted synthesis of new indophenazine 1, 3, 5-trisubstituted pyrrazoline derivatives of benzofuran and their antimicrobial activity. Bioorg. Med. Chem. Lett. 2009; 19: 2688-2692.

[3]. Ramanpreet et al. Benzimidazole derivatives-An overview, IJRPC 2011, 1(3).

[4]. Shukla, Synthesis and Biological Screening of benzimidazole derivatives ,IJPSR, 2012; Vol. 3(3): 922-927

[5]. Tupe AP*, Pawar PY, Mane BY, and Magar SD, Synthesis Analgesic and Anti-Inflammatory Activity of Some 2-Substituted 3Acetic Acid Benzimidazole Derivatives, RJPBCS, April-June 2013, Vol. 4 , Issue 2 ,Page No. 928

[6]. Sanahanbi N.* and T. Sivakumar, Synthesis of Some Schiff's Bases of 2-Methyl Benzimidazole Derivatives and Screening of Analgesic and Anti-Inflammatory Activities, CODEN(USA) : AJBPAD, Issue 2 (Vol. 4) 2013

[7]. Marriappan $G$ et al, Synthesis and evaluation of Mannich bases of benzimidazole derivatives, Indian Journal of Chemistry, vol.50B, September 2011, pp.1216-1219.

[8]. Sandeep Waghulde1, Ganesh Lonsane4, Varsha Borwandkar3, Sachin Laddha2, Synthesis and anti-inflammatory activity of novel 2-(Substituted alkyl or aryl pyridynyl) benzimidazole derivatives.

[9]. KF Ansari and C Lal*, Synthesis and biological activity of some heterocyclic compounds containing benzimidazole and betalactam moiety, J. Chem. Sci., Vol. 121, No. 6, November 2009, pp. 1017-1025.

[10]. Hamdan S. Al-Ebaisat., Synthesis and Biological Activities of Some Benzimidazoles Derivatives, J. Appl. Sci. Environ. Manage. Sept, 2011 Vol. 15 (3) $451-454$.

[11]. Chimirri A et al., Synthesis and biological activity of novel 1H,3H-thiazolo[3,4-a]benzimidazoles: non-nucleoside human immunodeficiency virus type 1 reverse transcriptase inhibitors, Antiviral Chemistry \& Chemotherapy 10:211-217.

[12]. M.S. Shingare*, D.V. Mane, D.B. Shinde, S.N. Thore and S.B. Bhawsar, Synthesis of Mannich Bases of Possible AntiViral Agents, Asian Journel of Chemistry, Vol.8, No.2(1996), 225-228.

[13]. K Sreena et al, Synthesis and Anthelmintic Activity of Benzimidazole Derivatives HYGEIA / Vol.1, No.1/March-Aug, 09.

[14]. Ramanpreet et al. Benzimidazole derivatives-An overview, IJRPC 2011, 1(3).

[15]. B Cakir, E Yildirim, T Ercanli, K Erol, MF Sahin, Synthesis and anticonvulsant activity of some (2:4-substituted) benzaldehyde (2-oxobenzothiazolin-3-yl) acetohydrazones, Farmaco, 1999, 54, 842-845.

[16]. Kalyankar TM *, Pekamwar SS, Wadher SJ, Tiprale PS and Shinde GH, Review on Benzimidazole Derivative, International Journal of Chemical and Pharmaceutical Sciences, 2012, Dec., Vol. 3 (4).

[17]. Kapuriya K., Ganure A., Davda S., Kitawala M., Topiya H., Benzimidazole: A promising Lead for AntiCancer Drug Design, UJP 2013, 02(03): Page 57-62.

[18]. Patil, A., Ganguly, S., Surana, S. , A systemic review of benzimidazole derivatives as an antiulcer agent. Rasayan Journal of Chemistry, 1(3): 447-460. 
[19]. Reddy BA., Synthesis and Characterization of Some Benzimidazole Derivatives using as Antihypertensive Agents., JPRHS 2010, 2(1): 103-113.

[20]. JB Wright. The chemistry of the benzimidazoles ,1951; 38: 397-541.

[21]. Uday Kalidhar*, Amandeep Kaur, An Overview on Some Benzimidazole and Sulfonamide Derivatives with Anti-Microbial Activity, RJPBCS, October-December 2011, Volume 2, Issue 4 Page No. 1116

[22]. Komal Petkar *, Pranav Parkh,Preeeti Mehta, Abha Kumar, Anjana Baro, Synthesis and evaluation of 2-chloromethyl-1Hbenzimidazole derivatives as antifungal agents Int J Pharm Pharm Sci, Vol 5, Issue 2, 115-119.

[23]. Soni B et al., Synthesis and evaluation of some new benzimidazole derivative as potent antimicrobial agents, Pharmacie Globale (IJCP) 2012, 9 (05).

[24]. Panneer Selvam et al., Synthesis of novel 2-substituted benzimidazole derivatives as potential anti microbial agents, Research in Biotechnology, 2(3):50-57, 2011.

[25]. Sugumaran et al. Synthesis and Biological Activity of Novel 2, 5-Disubstituted Benzimidazole Derivatives, IJPSDR JanuaryMarch, 2012, Vol 4, Issue 1 (80-83).

[26]. Sudheer Babu I et al. Synthesis, Characterization and Antimicrobial screening of some 1 -substituted benzimidazole derivatives ,Int.J.Pharm \& Ind. Res, Vol.02, Issue01, Jan-Mar 2012.

[27]. Kuldeep Kumar, Prof.(Dr). D. P. Pathak., Synthesis, Characterization and Evaluation For Antimicrobial Activity Of 2 Substituted Benzimidazole Derivatives., THE PHARMA INNOVATION., Vol. 1 No. 92012.

[28]. Davood Azarifar et al., Acetic acid-promoted condensation of $o$-phenylenediamine with aldehydes into 2-aryl-1-(arylmethyl)$1 H$-benzimidazoles under microwave irradiation., J. Serb. Chem. Soc. 75 (9) 1181-1189 (2010).

[29]. K.C.S. Achar et al., In-vivo analgesic and anti-inflammatory activities of newly synthesized benzimidazole derivatives., European Journal of Medicinal Chemistry 45 (2010) 2048-2054.

[30]. B. Yesu babu et al., Synthesis, Characterization And Evaluation Of AntiMicrobial Activity Of 2-Substituted Benzimidazoles., International Journal of Research in Pharmaceutical and Nano Sciences. 2(2), 2013, 234 - 241.

and D. P. Pathak., Synthesis of Benzimidazole Derivatives: As Anti-hypertensive Agents., E-Journal of Chemistry Vol. 3, No.4, pp 278-285, October 2006.

[32]. Avinash Patil, Swastika Ganguly and Sanjay Surana., Synthesis and antiulcer activity of 2-[5-substituted-1-H-benzo(d) imidazol-2-yl sulfinyl]methyl-3-substituted quinazoline-4-(3H) ones., J. Chem. Sci., Vol. 122, No. 3, May 2010, pp. 443-450. 